Forum $2021 \cdot 36: 418$

https://doi.org/10.1007/s12312-021-00979-0

Online publiziert: 7. September 2021

(c) Springer Medizin Verlag $\mathrm{GmbH}$, ein Teil von

Springer Nature 2021

\section{bremer \\ krebsgesellschaft}

\title{
Nach 33 Jahren Aufbau und Leitung der Bremer Krebsgesellschaft folgt der Ruhestand
}

\section{Am 1. August 2021 begann ein neuer Lebensabschnitt für Marie Rösler: der Ruhestand}

Bremer Krebsgesellschaft e.V.

Bremen, Deutschland

Sie hat 1988 ihre Tätigkeit im Onkologischen Netzwerk begonnen und war seit dem Antrieb und Mittelpunkt der Vereinigung mit dem heutigen Namen „Bremer Krebsgesellschaft e.V., Landesverband der Deutschen Krebsgesellschaft". 1997 bezog der Verein erstmalig eigene Räumlichkeiten. In 33 Jahren hat Marie Rösler unermüdlich Menschen mit Krebserkrankungen beraten und unterstützt, Benefizveranstaltungen organisiert, den Bremer Krebskongress organisiert, sich in die Fort- und Weiterbildung eingebracht, Kontakte geknüpft und ein Netzwerk aufgebaut. Für unzählige Menschen war und ist Marie Rösler die ver-

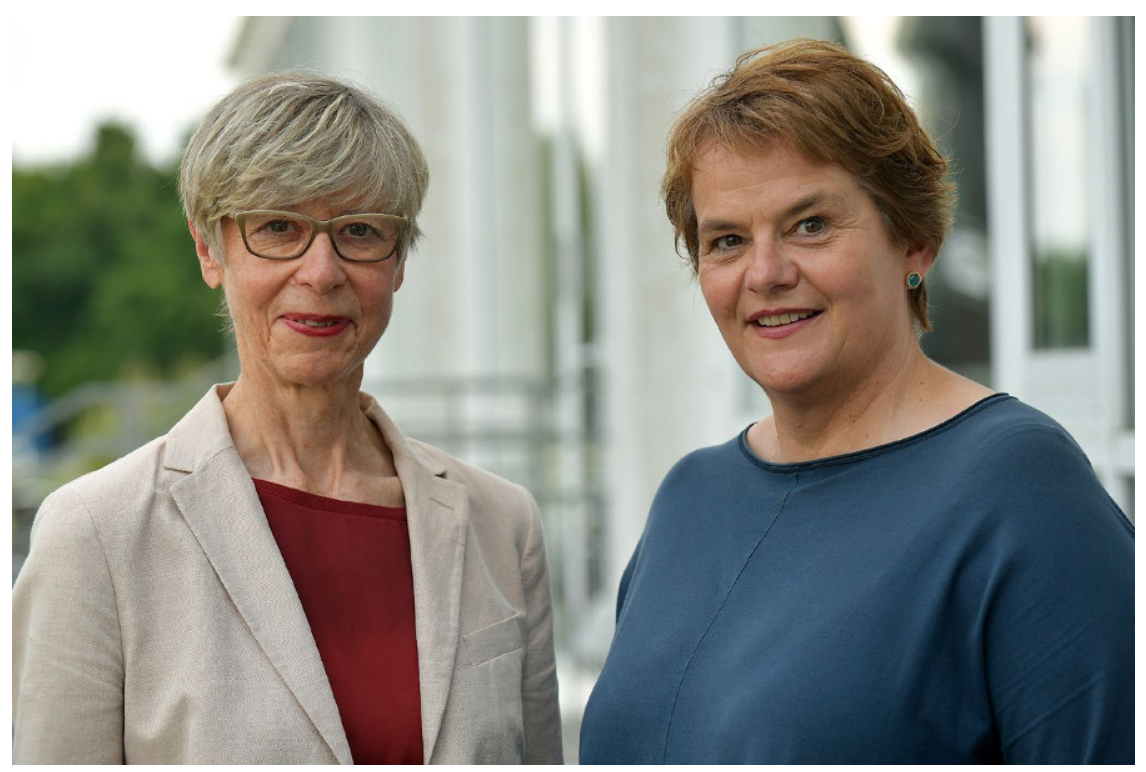

A Marie Rösler (li.) übergibt nach 33 Jahren die Leitung der Beratungsstelle der KG Bremen an Frau Dr. Susanne Hepe (๑ Bremer Krebsgesellschaft)

körperte Bremer Krebsgesellschaft. 2020 erhielt sie wegen ihrer herausragenden Leistungen das Bundesverdienstkreuz. Nun folgt der Ruhestand, allerdings nicht ohne Übergabe und Einarbeitung ihrer Nachfolgerin, Dr. med. Susanne Hepe.

Frau Dr. Hepe ist Fachärztin für Chirurgie. Nach 10 jähriger klinischer Tätigkeit in Oldenburg wechselte sie 2004 in die Bremer Ärztekammer und leitete die Akademie für Fortbildung. Während dieser Zeit entstand der Kontakt zur Bremer Krebsgesellschaft. Mit der Übernahme der Leitung der Beratungsstelle will sie sich beruflich noch einmal verändern. Die Beratung und
Unterstützung von Krebs betroffener Menschen ist ihr ein Anliegen. Einen weiteren Schwerpunkt ihrer Tätigkeit sieht sie in Präventionsangeboten. Für die Zukunft kann Frau Dr. Hepe auf ein eingespieltes Team und ein funktionierendes Netzwerk zurückgreifen und freut sich auf die neue Aufgabe.

\section{Korrespondenzadresse}

\section{Susanne Hepe}

Bremer Krebsgesellschaft - Landesverband der DKG e.V.

Am Schwarzen Meer 101-105,

28205 Bremen, Deutschland www.bremerkrebsgesellschaft.de 